Methods We calculated the SLICC scores (Systemic Lupus International Collaborating Clinics/American College of Rheumatology Damage Index) of 236 patients diagnosed as SLE between 1988 and 2000. Anti-ENA antibodies (U1-RNP, Sm, Ro, and La) were studied by ELISA in the first available serum sample for each patient. The SLE disease activity index (SLEDAI) of the first hospital study was calculated retrospectively.

Results Twenty-five (10.5\%) of the 236 patients were men. Age, age at onset of SLE, duration of the disease, and SLEDAI score at the onset of the disease were similar in the men and women. There was no difference in the frequency of anti-ENA antibodies between the sexes. The SLICC cumulative tissue damage score obtained at the last follow-up visit was significantly higher in men $(2.24$; SD 1.89) than in women (1.40; SD 1.86) (MannWhitney p:0.009). Kidney disease, whether characterised by clearance of less than $50 \%$ of normal ( 9 of $25 ; 36 \%$ vs 23 of $211 ; 10.9 \%)$ (OR: 4.5 ) or proteinuria over $3.5 \mathrm{~g} /$ day and need for dialysis and transplantation (14 of $25 ; 56 \%$ vs 49 of 211 ; 23.2\%) (OR: 4.2), was significantly more frequent in men (OR: 3.8). Cardiomyopathy (3 of $25 ; 12 \%$ vs 3 of $211 ; 1.4 \%$ ) (OR: 9.4), avascular necrosis ( 3 of $25 ; 12 \%$ vs 3 of $211 ; 1.4 \%)$ (OR: 9.4), and retinal disorders (2 of $25 ; 8 \%$ vs 1 of $211 ; 0.5 \%$ ) (OR: 18.2) also were more frequent in men than women. In the follow-up period, 5 of the 25 men died (20\%) but only 3 of the 211 women died (1.4\%) (Fisher p:0.005; OR: 17.33; IC 95\%: 3.8-77.9).

Conclusion Mortality and the tissue damage scores were significantly greater in men with SLE than in women. The higher SLICC score was due mainly to the greater frequency of kidney and heart disease.

\section{OP0104 LUPUS NEPHRITIS: CONTRASTING CLINICAL OUTCOME DURING THE LAST DECADE}

${ }^{1} \mathrm{C}$ Fiehn, ${ }^{1} \mathrm{Y}$ Hajjar, ${ }^{2} \mathrm{R}$ Waldherr, ${ }^{3} \mathrm{~K}$ Andrassy. ${ }^{1}$ Department Internal Medicine $\mathrm{V}_{;}{ }^{2} \mathrm{Cl}$ linic of Pathology, Heidelberg, Germany; ${ }^{3}$ Section of Nephrology, University of Heidelberg

\subsection{6/annrheumdis-2001.188}

Background According to Cameron (1999) 5-year renal survival of WHO class IV lupus nephritis (LN) after diagnosis and treatment is now $82 \%$. It is claimed that when terminal renal failure (ERF) supervenes, it is within the first decade of follow-up.

Objectives As our recent experience is different, we evaluated the long-term renal outcome in patients with lupus nephritis treated in our institution in the last decade.

Methods During the last 10 years we followed 44 caucasians (35 females, 9 males, median age 40 years, range 18-73) with biopsy proven LN (WHO class II 5, III 2, IV 31, V 5, and VI 1). 15/44 patients had hypertension, 37/44 patients anti-DNA-ab (Farr test) (median 18, range $8-1493 \mathrm{U} / \mathrm{ml}$ ), $41 / 44$ positive ANA (median 1280, range 160-40960 titer), 44/44 proteinuria (20/44 with nephrotic proteinuria (NS) and 37/44 hematuria. Median creatinine on admission was $0.9 \mathrm{mg} / \mathrm{dl}$, range (0.3-4.0), median haemoglobin $11.7 \mathrm{~g} / \mathrm{dl}$ (range 8.2-14.3). All WHO classes were treated with glucocorticoids $(1 \mathrm{mg} / \mathrm{kg} / \mathrm{day}$ for $8-12$ weeks, tapering off according to the clinical situation). WHO class IV was initially treated with 3 methylprednisolone boli (then $1 \mathrm{mg} / \mathrm{kg} /$ day) and cyclophosphamide (CP) (Austin scheme), sometimes supported by cyclosporine, azathioprine or mycophenolate mofetil. Hypertension and/or NS were treated with ACE inhibitors, hyperlipidemia with statins.
Results No patient died or attained ERF. Median creatinine was $1.1 \mathrm{mg} / \mathrm{dl}$ (range 0.5-5.4) after an median observation period of 39 month (range 1-128). Impaired but stable renal function was observed in 12/44 patients (classes III 2, IV 9, V 1). Progression to renal failure was observed in 1 patient with uncontrolled hypertension. From renal histology only classes III and IV had adverse outcomes.

Conclusion We attribute improved outcome of $\mathrm{LN}$ in the last decade to earlier detection and therapy of LN and treatment of LN-flares with CP and steroid boli. Moreover better medical management particularly the consequent treatment of hypertension with ACE inhibitors may contribute to a favourable prognosis.

\section{REFERENCES}

1 Cameron JS. Lupus nephritis. J Am Soc Nephrol. 1999;10:413-35

2 Austin HA, Boumpas DT, Vaughan EM, Balow JE. High-risk features of lupus nephritis: importance of race and histological factors in 166 patients. Nephrol Dial Transplant. 1995;10:1620-8

3 Moroni G, Quaglini S, Maccario M, Banfi G, Ponticelli C. Nephritic flares are predictors of bad long-term renal outcome in lupus nephritis. Kidney Int. 1996;50:2047-53

4 Ward MM, Studenski S. Clinical prognostic factors in lupus nephritis. The importance of hypertension and smoking. Arch Intern Med. 1992;152:2082-8

\section{Vasculitis}

\section{AB0082 BEHCET'S DISEASE COMPLICATED WITH CELIAC TRUNK ANEURYSM}

G Basaranoglu, M Basaranoglu. Anesthesiology, Vakif Gureba Hospital, Istanbul, Turkey

10.1136/annrheumdis-2001.189

Background The aneurysms of the celiac trunk are the rarest aneurysms of the visceral arteries. Spontaneous celiac trunk aneurysm has not been described previously in Behcet's disease.

Objectives A 19-yr-old Turkish man was admitted to our hospital with a history of abdominal pain for 2 weeks. He described recurrent attacks of ulcerations of the oral and genital mucosa, blurred vision and painful lesions on the front of the legs for 2 years. He had had abdominal pain for 6 months, but this symptom had become more troublesome in the last 2 weeks. Physical examination revealed no pathology except for mild abdominal tenderness and deeply pigmented areas on the front of the legs. Ophthalmologic examination showed ocular inflammation and retinal vasculitis. Laboratory evaluations revealed haemoglobin of $14.4 \mathrm{~g} / \mathrm{dl}$, white blood cell count of 9650 cells/mm and platelet count of $470000 \mathrm{cells} / \mathrm{mm}$. The erythrocyte sedimentation rate was $61 \mathrm{~mm} / \mathrm{h}$, C-reactive protein $11.5 \mathrm{mg} / \mathrm{l}$ (normal $<0.8$ $\mathrm{mg} / \mathrm{l}$ ), and fibrinogen $422 \mathrm{mg} / \mathrm{dl}$ (normal: 200-400 mg/dl for male). HLA-B51 is positive. Pathergy test is positive. Celiac trunk aneurysm was detected by computed tomography. A selective angiogram showed dilatation of the celiac artery and an aneurysm with a diameter $4^{\prime} 2 \mathrm{~cm}$.

Methods Visceral artery aneurysm is a rare, but important form of vascular pathology. Aneurysms of splenic artery are the most common. Aneurysms of the celiac artery are uncommon and account for $4 \%$ of all splanchnic aneurysms. They can rupture in $2-50 \%$ of the cases with a mortality rate of around $80 \%$. The most common etiologic factor of celiac artery aneurysms is atherosclerosis; other causes include infection, trauma, polyarteritis nodosa and fibromuscular dysplasia. 